\title{
Electrophoresis and spectrometric analyses of adaptation-related proteins in thermally stressed Chromobacterium violaceum
}

\author{
I.B. Cordeiro ${ }^{1}$, D.P. Castro ${ }^{7}$, P.P.O. Nogueira ${ }^{7}$, P.C.S. Angelo ${ }^{6}$, \\ P.A. Nogueira ${ }^{7}$, J.F.C. Gonçalves ${ }^{8}$, A.M.R.F. Pereira ${ }^{9}$, J.S. Garcia ${ }^{2,3}$, \\ G.H.M.F. Souza ${ }^{2,4}$, M.A.Z. Arruda ${ }^{5}$, M.N. Eberlin' ${ }^{2}$, S. Astolfi-Filho', \\ E.V. Andrade ${ }^{1}$ and J.L. López-Lozano ${ }^{10}$
}

\author{
${ }^{1}$ Laboratório de Biologia Molecular, Centro de Apoio Multidisciplinar, \\ Universidade Federal do Amazonas, Manaus, AM, Brasil \\ ${ }^{2}$ Laboratório Thomson de Espectrometria de Massas, Instituto de Química, \\ Universidade Estadual de Campinas, Campinas, SP, Brasil \\ ${ }^{3}$ Instituto de Química, Universidade Federal de Alfenas, Alfenas, MG, Brasil \\ ${ }^{4}$ Research and Development Laboratory, Mass Spectrometry Applications, \\ Waters Corporation, São Paulo, SP, Brasil \\ ${ }^{5}$ Laboratório de Espectrometria, Preparo de Amostras e Mecanização, \\ Instituto de Química, Universidade Estadual de Campinas, \\ Campinas, SP, Brasil \\ ${ }^{6}$ Embrapa Amazônia Ocidental, Manaus, AM, Brasil \\ ${ }^{7}$ Coordenação de Biodiversidade em Saúde, \\ Centro de Pesquisa Leonidas e Maria Deane - Fundação Oswaldo Cruz, \\ Manaus, AM, Brasil \\ ${ }^{8}$ Laboratório de Fisiologia e Bioquímica Vegetal, \\ Instituto Nacional de Pesquisas da Amazônia, Manaus, AM, Brasil \\ ${ }^{9}$ Laboratório de Leishmanioses e Doença de Chagas, \\ Departamento de Ciências da Saúde, Divisão de Parasitologia I, \\ Instituto Nacional de Pesquisas da Amazônia, Manaus, AM, Brasil \\ ${ }^{10}$ Laboratório de Bioquímica e Imunologia de Venenos de Serpentes, \\ Gerência de Animais Peçonhentos, \\ Fundação de Medicina Tropical do Amazonas, Manaus, AM, Brasil \\ Corresponding author: E.V. de Andrade \\ E-mail: edandrade@ufam.edu.br / edandrade2003@yahoo.com.br
}


Genet. Mol. Res. 12 (4): 5057-5071 (2013)

Received March 12, 2013

Accepted September 16, 2013

Published October 29, 2013

DOI http://dx.doi.org/10.4238/2013.October.29.1

\begin{abstract}
Chromobacterium violaceum is a Gram-negative proteobacteria found in water and soil; it is widely distributed in tropical and subtropical regions, such as the Amazon rainforest. We examined protein expression changes that occur in $C$. violaceum at different growth temperatures using electrophoresis and mass spectrometry. The total number of spots detected was 1985; the number ranged from 99 to 380 in each assay. The proteins that were identified spectrometrically were categorized as chaperones, proteins expressed exclusively under heat stress, enzymes involved in the respiratory and fermentation cycles, ribosomal proteins, and proteins related to transport and secretion. Controlling inverted repeat of chaperone expression and inverted repeat DNA binding sequences, as well as regions recognized by sigma factor 32 , elements involved in the genetic regulation of the bacterial stress response, were identified in the promoter regions of several of the genes coding proteins, involved in the $C$. violaceum stress response. We found that $30^{\circ} \mathrm{C}$ is the optimal growth temperature for $C$. violaceum, whereas 25,35 , and $40^{\circ} \mathrm{C}$ are stressful temperatures that trigger the expression of chaperones, superoxide dismutase, a probable small heat shock protein, a probable phasing, ferrichrome-iron receptor protein, elongation factor $\mathrm{P}$, and an ornithine carbamoyltransferase catabolite. This information improves our comprehension of the mechanisms involved in stress adaptation by $C$. violaceum.
\end{abstract}

Key words: CIRCE; Chaperones; Heat shock response; HSP; Differential gene expression

\title{
INTRODUCTION
}

Chromobacterium violaceum (Bergonzini, 1881) is a Gram-negative $\beta$-proteobacterium that grows in a variety of ecosystems in tropical and subtropical areas (Lima-Bittencourt et al., 2011). In Brazil, it is largely found in the water and on banks of the Rio Negro in Amazonas State. C. violaceum has been largely investigated due to its potential use for biotechnological purposes, and its complete genome was sequenced in 2003 by the Brazilian National Genome Project Consortium. This sequencing revealed a total of 4,751,080 base pairs and 4430 ORFs (open reading frames), many of which suggest that $C$. violaceum could have biotechnological applications. Several ORFs likely participating in the organism's stress response were identified, including ORFs involved in heat shock protein signal transduction, iron metabolism, cell transport, oxidation and UV light responses (Vasconcelos et al., 2003; Hungria et al., 2004). Collectively, this supports the idea that this bacterium is highly adaptable. Although all these 
proteins may be involved in the response of $C$. violaceum to stressful environmental conditions, their specific roles are poorly understood.

Many of the stress responses overlap with one another in bacteria (Ishibashi et al., 2010) and adaptive reactions involve general changes in metabolism as well as in gene transcript levels (Jozefczuk et al., 2010; Gomes et al., 2012). The expression of heat shock genes in Gram-negative proteobacteria is positively modulated by the transcriptional regulator $\mathrm{RpoH}$, the $\sigma^{32}$ subunit of RNA polymerase, which induces the expression of proteins involved in the response to heat and cold stress (Yura et al., 1993; El-Samad et al., 2005). Some of these proteins are chaperones and others heat shock proteins, which are responsible for the folding, assembly, translocation and degradation of proteins in the cell under physiological conditions, and can also assist in cellular protein refolding under stress. In turn, many thermal sensors are components of cellular structures that are damaged or altered by heat, such as ribosomes, DNA, intracellular proteins and, less commonly, membrane components (Rowbury, 2005).

Genome analysis is not sufficient to generate a complete picture of the heat-related stress response as it does not reveal the levels of gene expression. Proteomic studies following genomic and transcriptomic analyses have been described for prokaryotes (Broberg and Clark, 2010; Hamon et al., 2011) and eukaryotes (Rossignol et al., 2009). Together, these studies aim to improve our understanding of numerous diverse cellular processes, including those involving abiotic stress (Hongsthong et al., 2008; Woo et al., 2009). Here, the main goal was to identify proteins involved in the adaptation of $C$. violaceum (ATCC12472) subjected to stressful temperature conditions. To evaluate the response of $C$. violaceum to thermal stress, we tested the hypothesis that 25,35 and $40^{\circ} \mathrm{C}$ would be stressful growth temperatures, whereas $30^{\circ} \mathrm{C}$ would be the optimal growth temperature for this organism. Proteins related to thermal stress were identified by mass spectrometry and their putative roles during the adaptation process are discussed.

\section{MATERIAL AND METHODS}

\section{Bacterial cultivation and protein extraction}

Individual colonies of $C$. violaceum (ATCC12472) were grown in $1 \mathrm{~L} \mathrm{LB}$ (LuriaBertani) medium, $\mathrm{pH} 7.0$, with aeration at $25,30,35$ and $40^{\circ} \mathrm{C}$ and at $200 \mathrm{rpm}$. Absorbance at $590 \mathrm{~nm}$ was monitored hourly up to $34 \mathrm{~h}$, and the resulting measurements were plotted to obtain growth curves. Total protein extracts for two-dimensional electrophoresis (2-DE) analysis were obtained after $7 \mathrm{~h}$ (exponential phases) and $19 \mathrm{~h}$ (stationary phases) of cultivation. $C$. violaceum cells were harvested by centrifugation at $2700 \mathrm{~g}$ for $15 \mathrm{~min}$ at $4^{\circ} \mathrm{C}$. The cells were washed twice with $25 \mathrm{~mL} 0.15 \mathrm{M} \mathrm{NaCl}$, and $100 \mathrm{mg}$ cell pellet (wet weight) were transferred to microtubes and washed twice in $1 \mathrm{~mL}$ Milli-Q ultrapure water containing $2 \mathrm{mM}$ PMSF and a protease inhibitor cocktail (Amersham Biosciences, USA). The pelleted cells were processed immediately or stored at $-80^{\circ} \mathrm{C}$. Cells were resuspended in lysis buffer ( $8 \mathrm{M}$ urea, $2 \%$ CHAPS, $0.5 \%$ IPG buffer, $100 \mathrm{mM}$ DTT and $80 \mathrm{mM}$ citric acid) in the presence of protease inhibitor cocktail and disrupted using a syringe. The resulting cell extract was centrifuged at $28,000 \mathrm{~g}$ for $20 \mathrm{~min}$ at $25^{\circ} \mathrm{C}$. The soluble fractions from each tube were mixed to ensure the homogeneity of the samples and redistributed in aliquots of $200 \mu \mathrm{L}$. The protein extract was precipitated in 5 volumes of $100 \%$ acetone, incubated for $1 \mathrm{~h}$ at room temperature and centri- 
fuged at $7000 \mathrm{~g}$ for $10 \mathrm{~min}$ at $25^{\circ} \mathrm{C}$. The pellet was washed twice in an $80 \%$ acetone solution and then centrifuged under the same conditions described above. The protein extracts were analyzed immediately or stored at $-20^{\circ} \mathrm{C}$. Extracts were resuspended in $500 \mu \mathrm{L}$ Tris-glycine buffer and protein concentration was estimated using the BCA protein assay kit (BioAgency, Brazil) according to the manufacturer instructions. Bovine serum albumin (Sigma, USA) was used as the standard.

\section{2-DE gel}

2-DE was performed using a standard procedure (O'Farrel, 1975) with modifications. The protein extract $(250 \mu \mathrm{g})$ was resuspended in $250 \mu \mathrm{L}$ DeStreak Rehydration Solution (GE Healthcare, Sweden) in the presence of 0.5\% IPG buffer 3-11 NL (GE Healthcare) and loaded onto an immobilized $\mathrm{pH}$ gradient strip (3-11 NL) by passive in-gel rehydration ( $10 \mathrm{~h})$. Isoelectric focusing (IEF) was performed at $20^{\circ} \mathrm{C}$ in IPGPhor3 (GE Healthcare) as follows: $150 \mathrm{~V}(2 \mathrm{~h}$ ), $300 \mathrm{~V}(2 \mathrm{~h}), 1000 \mathrm{~V}$ (gradient for $4 \mathrm{~h}$ ), $8000 \mathrm{~V}$ (gradient for $2 \mathrm{~h}$ ) and $8000 \mathrm{~V}(2 \mathrm{~h})$. The proteins on the IPG strips were reduced and alkylated for the second dimension separation, which was performed on $12 \%$ SDS polyacrylamide gels in the SE600Rub System $(18 \times 16 \mathrm{~cm}$ - GE Healthcare) at $50 \mathrm{~mA}$. Polyacrylamide gels were fixed using 10\% acid acetic and $40 \%$ methanol, followed by staining with Colloidal Coomassie Blue ( $8 \%$ ammonium sulfate, $0.8 \%$ phosphoric acid, $0.08 \%$ Coomassie Blue G-250 and 20\% methanol). Destaining was performed with deionized water. Gel images were captured by scanning (Image Scanner - GE Healthcare), and the images were analyzed with the Image Master Platinum software (Version 6). Three reproducible gels (over $70 \%$ in similarity) were run corresponding to at least two independent extraction procedures from each experimental condition. Spot counts were obtained according to the saliency and smooth parameters, which were equal to 100 and 2, respectively. The gel with the highest number of spots was regarded as the reference gel. Differentially expressed proteins were determined based on the ImageMaster Platinum software (Version 6) analysis.

\section{MALDI microplate preparation and analysis by mass spectrometry (MALDI Q-TOF/MS/MS)}

Spots of interest were subjected to in-gel tryptic digestion (Porcine Pancreas Trypsin, Sigma) and analyzed by mass spectrometry. Protein spot digestion was performed according to the manufacturer recommendations using the Montage In-Gel Digest ${ }_{\mathrm{ZP}}$ kit (Millipore, USA) in 96-deep-well Zip Plates (ZipPlate, Millipore). Three microliters of each sample (obtained by tryptic digestion) were applied onto a microplate using the dried droplet method (Karas and Hillenkamp, 1988). The matrix was added to the sample with a total volume of $1.2 \mu \mathrm{L}$ and was then air dried at room temperature. This matrix solution was prepared using $\alpha$-cyano-4-hydroxycinnamic acid (Beavis et al., 1992) in a 1:1 (v/v) acetonitrile/ $\mathrm{H}_{2} \mathrm{O}$ solution containing $0.1 \%(\mathrm{v} / \mathrm{v})$ TFA. MALDI Q-TOF mass spectra were acquired in a MALDI Q-Tof Premier mass spectrometer (Waters-Micromass, UK). Mass spectra were obtained with a solid state laser operated in positive mode (LDI+). Real-time calibration was performed with lock mass correction using a mixture of PEG oligomers (PEG 600, 1000, 1500 and 2000). Each spectrum was collected over a $1 \mathrm{~s}$ scan and the spectra were accumulated over approximately $2 \mathrm{~min}$. The instrument was controlled by MassLynx 4.1v software. All mass spectra were processed into "peak list" files with a *.pkl exten- 
sion using the ProteinLynxGlobalServer 2.3v (Waters Corporation, UK). Protein identification was performed by searching a database using the peptide peak list (*.pkl file) mass and intensity files generated by MALDI Q-TOF. The $C$. violaceum databank was compiled with a random databank called 10X_Random_SwissProt via the ProteinLynxGlobal Server 2.3v. Monoisotopic peak lists were processed with the following search parameters: one missed cleavage, tryptic digestion and carbamidomethylation as a cysteine modification. The search error tolerance was set at $5 \mathrm{ppm}$ with a $[\mathrm{M}+\mathrm{H}]^{+}$charge state after spectral deconvolution.

\section{RESULTS}

Analyses of the proteomic profiles of C. violaceum grown at $25,30,35$ and $40^{\circ} \mathrm{C}$ were performed to improve our knowledge about this organism's adaptive responses to thermal stress (Figure 1). The numbers of spots visualized by 2-DE using proteins extracted from cultures maintained at $25,30,35$ and $40^{\circ} \mathrm{C}$ in the exponential growth phase were $254,99,214$ and 336, respectively. For the samples in stationary phase, the numbers of spots were 160, 235, 307 and 380, respectively (Figure 2). Together, the total of spots detected was 1985.

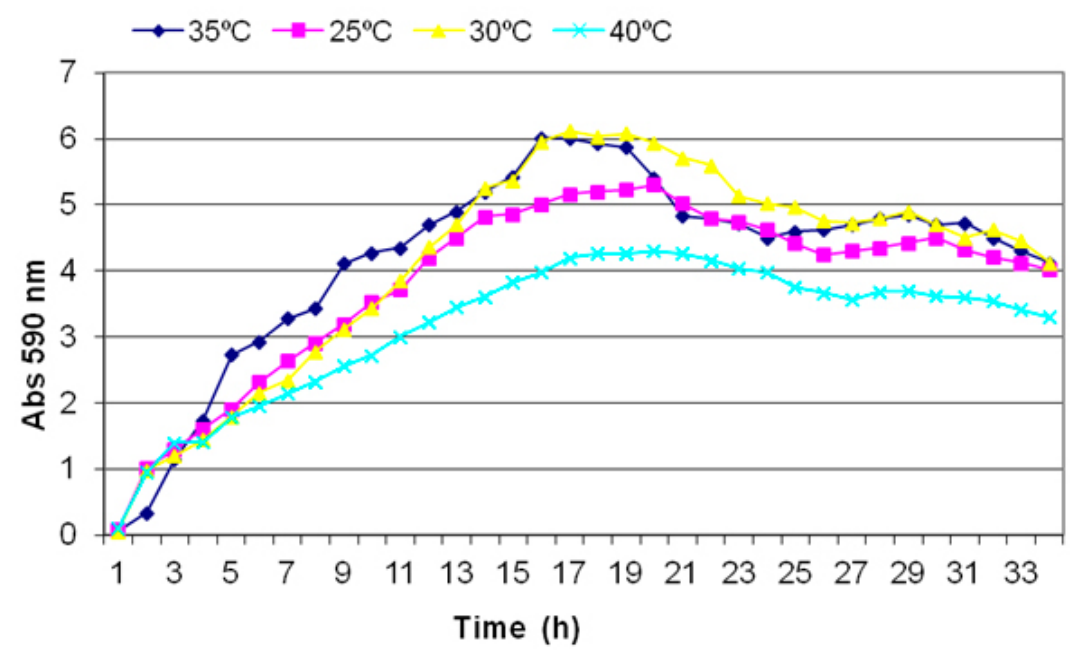

Figure 1. Chromobacterium violaceum cultured under different temperatures. Individual colonies of C. violaceum (ATCC12472) were grown in $1 \mathrm{~L} \mathrm{LB}$ (Luria-Bertani) medium, $\mathrm{pH} 7.0$, with aeration at 25, 30, 35, and $40^{\circ} \mathrm{C}$ at 200 $\mathrm{rpm}$. The absorbance at $590 \mathrm{~nm}$ was monitored hourly up to $34 \mathrm{~h}$, and the resulting measurements were plotted to obtain growth curves.

After a comparative analysis of the 2-DE gels from all conditions, 93 spots were selected for mass spectrometry (MS) analysis (Figure 2). Thirty-two proteins were identified as modulated by temperature and/or growth phase. Of those, 21 proteins were observed in all conditions tested, but at different intensities. The other 11 were absent in gels from at least one of conditions tested and showed variation in their intensity when observed (Table 1). Proteins identified were categorized into six groups: chaperones, proteins expressed exclusively under heat stress, enzymes that participate in the respiratory and fermentation cycles, ribosomal proteins and proteins related to transport/secretion and membrane. 
A1. $25^{\circ} \mathrm{C}, 7$ hours

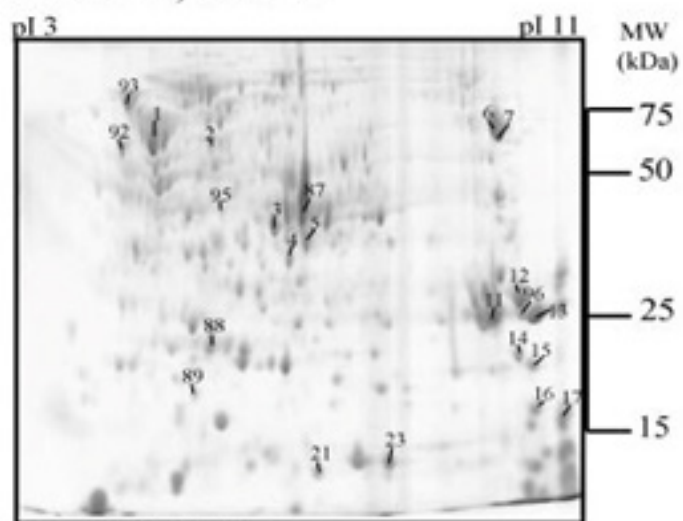

\section{B1. $30^{\circ} \mathrm{C}, 7$ hours}

pl 3

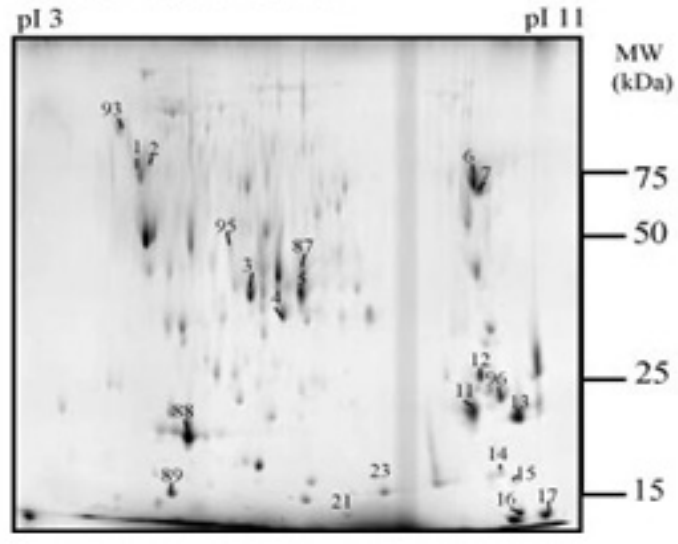

A2. $25^{\circ} \mathrm{C}, 19$ hours

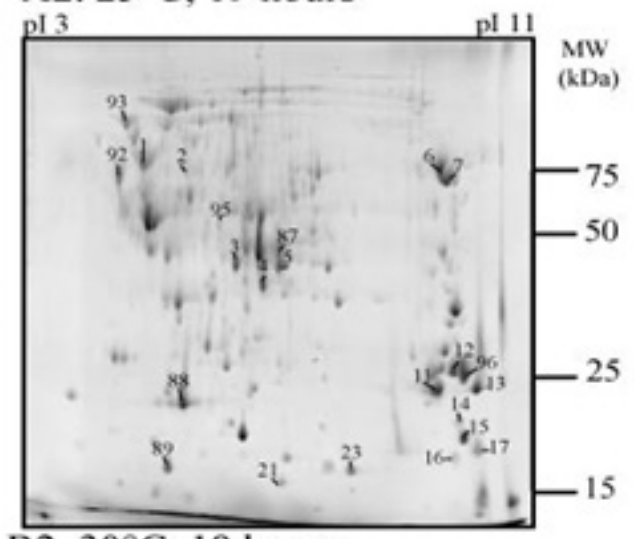

B2. $30^{\circ} \mathrm{C}, 19$ hours

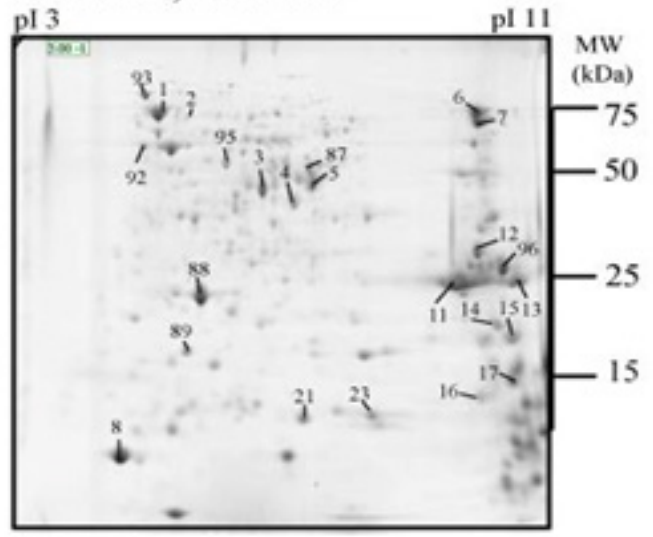

Figure 2. A proteomic map of Chromobacterium violaceum grown under different temperatures. For all conditions, $250 \mu \mathrm{g}$ soluble protein was used. For the first dimension separation, an immobilized $\mathrm{pH}$ gradient from 3 to $11 \mathrm{NL}$ was used. For the second dimension, protein separation was carried out by vertical SDS PAGE (12\%). The gels were stained with colloidal Coomassie blue. The spots identified were numbered according to their identification by mass spectrometry. Experimental growth conditions are indicated at the top of each gel.

\section{Chaperones}

Three chaperones were identified in C. violaceum under all assayed conditions (Table 1 and Figure 3): DnaK (CV1643), GroEL1 (CV4014) and GroEL2 (CV3233). Compared to cells growing at the non-stressful temperature of $30^{\circ} \mathrm{C}$, a tenfold increase in the expression level of GroEL1 was observed in cells grown at $35^{\circ} \mathrm{C}$ (stationary phase) and $40^{\circ} \mathrm{C}$ (exponential phase). Both GroEL2 and DnaK chaperones were expressed at a lower rate compared to GroEL1. The higher expression of GroEL2 was observed at $40^{\circ} \mathrm{C}$ in the stationary phase, and for DnaK, the variation under different experimental conditions was not considered relevant. In addition, the probable small heat shock protein (CV1177) was identified at 35 and $40^{\circ} \mathrm{C}$ (exponential and stationary phases) (Table 1 ). 
Proteomic analysis of $C$. violaceum under heat stress

5063

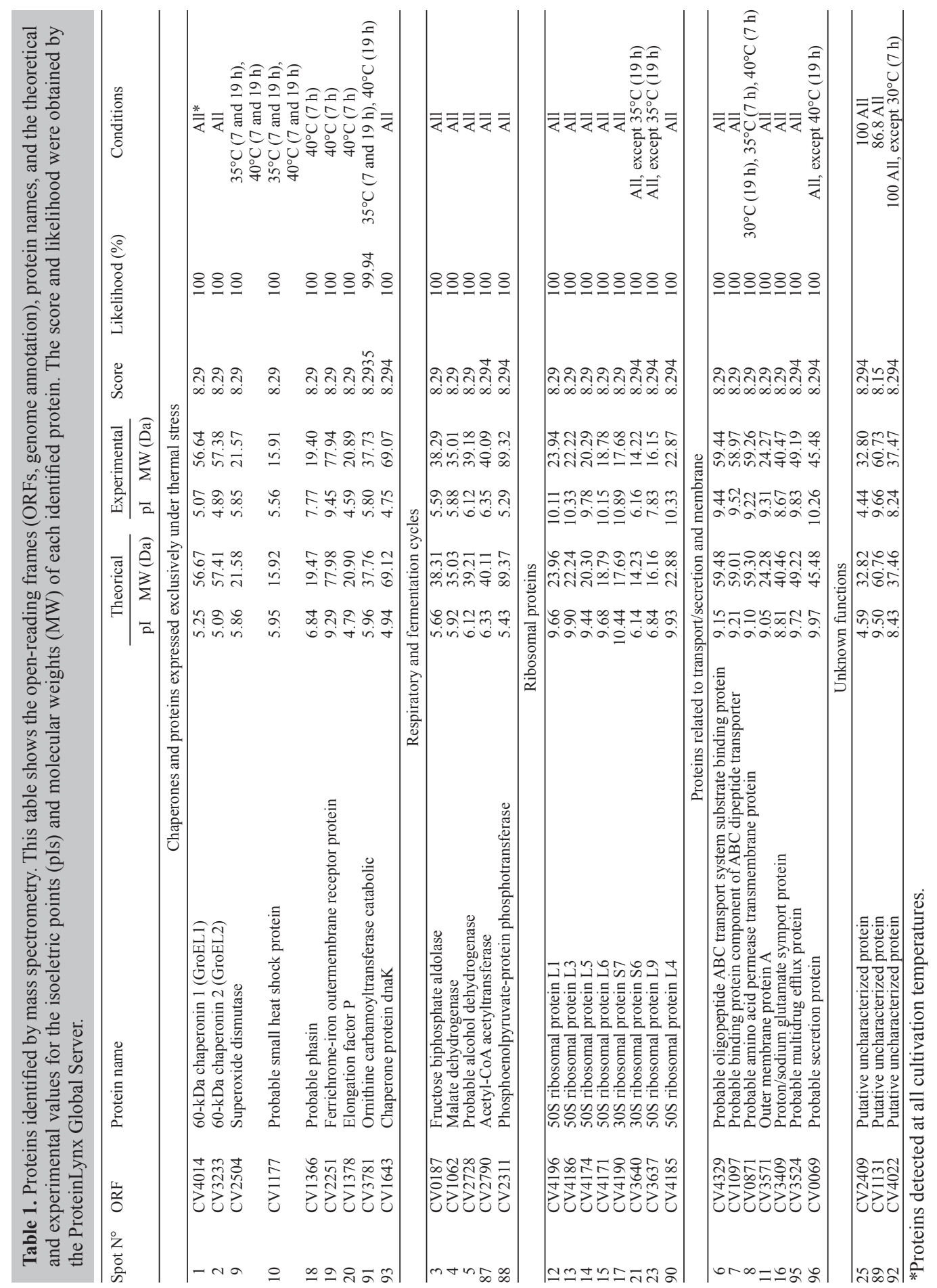

Genetics and Molecular Research 12 (4): 5057-5071 (2013)

CFUNPEC-RP www.funpecrp.com.br 
Promoter regions of the chaperone genes groEL1, groEL2, dnaK and the probable small heat shock protein exhibit regions that are likely recognized by the heat shock $\sigma^{32}$ sigma factor (Table 2). For groEL1, the IR (inverted repeat) sequence (GCACct- ${ }_{12}$-agGTGC) represents a potential CIRCE, although it was distinct from the bacterial consensus sequence (GCACTC-N ${ }_{9}$-GAGTGC) (Zuber and Schumman, 1994), as indicated by lower case. No CIRCE-related sequence was identified in the groEL2 and dnaK genes.

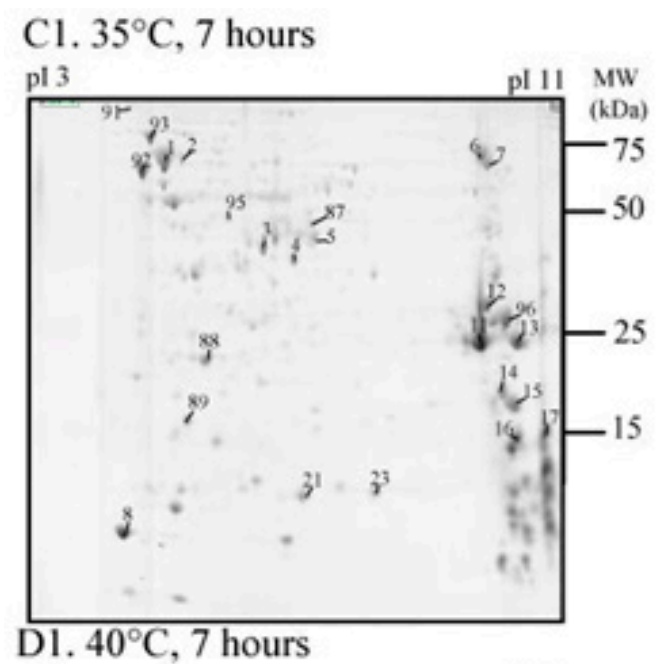

\section{C2. $35^{\circ} \mathrm{C}, 19$ hours}
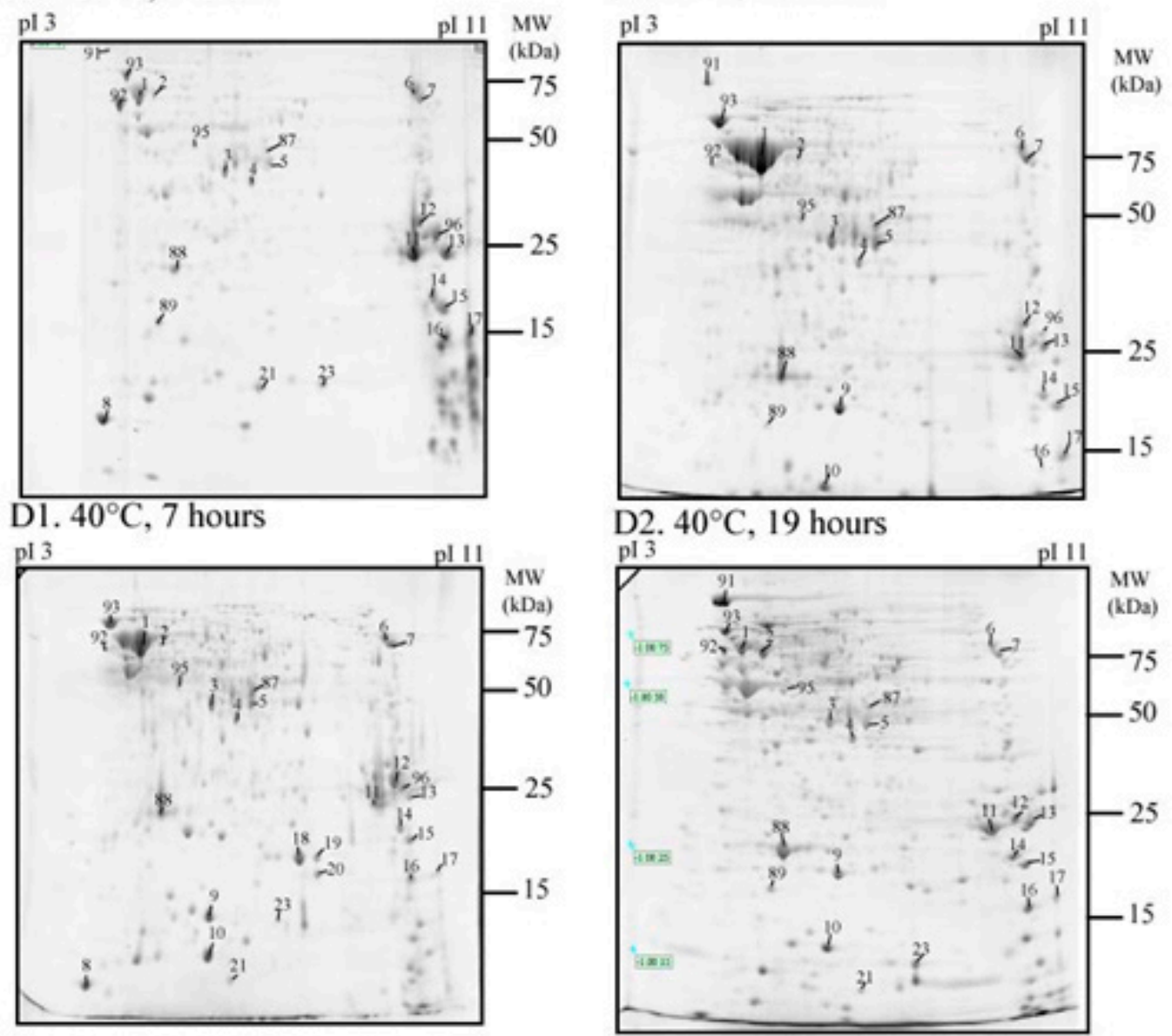

Figure 3. Chaperones of Chromobacterium violaceum that are involved in the heat stress response. The values (\% vol) were determined by Image Master Platinum. The spots that were identified under each experimental condition are shown in detail.

\section{Proteins expressed exclusively under heat stress}

Six proteins showed expression related to stressful temperatures above $30^{\circ} \mathrm{C}$. Three proteins were identified only in cells grown at $40^{\circ} \mathrm{C}$ in the exponential phase: a probable phasin (CV1366), a ferrichrome-iron outer membrane receptor protein, a siderophore trans- 
porter (CV2251, gene fhuA) and elongation factor P (CV1378). A less-specific response was observed for ornithine carbamoyltransferase (CV3781) and superoxide dismutase (CV2504). Ornithine carbamoyltransferase was identified in the exponential and stationary phases in cells grown at $35^{\circ} \mathrm{C}$, as well as in the stationary phase in cells grown at $40^{\circ} \mathrm{C}$. Superoxide dismutase was identified at the exponential and stationary phases in cells grown at 35 and $40^{\circ} \mathrm{C}$. The probable regulatory regions of the genes coding for ferrichrome-iron outer membrane receptor protein, phasin and superoxide dismutase had sequences likely recognized by the heat shock $\sigma^{32}$ sigma factor (Table 2). Probable small heat shock protein, even expressed exclusively under heat stress in this work, is discussed in the section about chaperones.

\begin{tabular}{|c|c|c|c|c|}
\hline Gene (protein name) & -35 box & Spaced region & -10 box & bp to ATG \\
\hline \multirow[t]{2}{*}{ shsp (Small heat shock) } & TTGAAt & 12 & GTCCCTATcT & 52 \\
\hline & TcGAcA & 21 & -AagCCcaTga & 17 \\
\hline \multirow[t]{2}{*}{ groEL1 (GroEL1) } & TTGAAg & 14 & GGCCgCAagg & 37 \\
\hline & TTGAAg & 6 & aTCCCaATcc & 47 \\
\hline \multirow[t]{2}{*}{ groEL2 (GroEL2) } & TgtAAt & 19 & GACCCTtTcc & 34 \\
\hline & TTGAgt & 5 & & 34 \\
\hline fhuA (Ferrichrome iron) & TaGAtA & 12 & GAtCaaggTaa & 41 \\
\hline \multirow[t]{2}{*}{ cv1366 (Phasin) } & TTtAcg & 12 & GCgCaCAaTa & 55 \\
\hline & TcaAcg & 13 & GACCCCATTT & 23 \\
\hline $\operatorname{dnaK}(\mathrm{DnaK})$ & TTGAAA & 11 & GCCaаTATTT & 68 \\
\hline \multirow{2}{*}{$\operatorname{sodB1}(\mathrm{SOD})$} & TTGcAA & 11 & -TatCatTTTa & 90 \\
\hline & TTGgcc & 11 & -AttCCAgTaa & 55 \\
\hline $\operatorname{grp} E(1642)^{* *}$ & TTGAAA & 11 & GTCCCTAccT & 24 \\
\hline CONSENSUS E. coli* & TTGAAA & $11-12$ & GNCCCCATWT & Variable \\
\hline CONSENSUS C. violaceum & TTGAAA & Variable & GNCCCYATTT & Variable \\
\hline
\end{tabular}

*The consensus sequence for the $\sigma^{32}$ sigma factor of $E$. coli (Nonaka et al., 2006). **Proteins related to the heat shock response that have been described in the $C$. violaceum genome, but were not identified here by mass spectrometry. $\mathrm{N}=\mathrm{A} / \mathrm{C} / \mathrm{G} / \mathrm{T} ; \mathrm{Y}=\mathrm{C} / \mathrm{T} ; \mathrm{W}=\mathrm{A} / \mathrm{T}$.

\section{Enzymes involved in the respiratory and fermentation cycles}

Five enzymes related to glycolysis and the tricarboxylic acid cycle, central metabolic pathways, were identified: fructose bisphosphate aldolase (CV0187), malate dehydrogenase (CV1062), acetyl-CoA acetyltransferase (CV2790), a probable alcohol dehydrogenase (CV2728) and phosphoenol pyruvate phosphotransferase (CV2311) (Table 1). These enzymes were expressed by $C$. violaceum under all the experimental conditions, although their levels of expression were affected by the temperature and phase of bacterial growth (Figure 4). Though all proteins displayed a complex expression pattern, the highest expression levels of these proteins were observed in cultures grown at $30^{\circ} \mathrm{C}$ in the exponential phase.

\section{Ribosomal proteins}

Eight ribosomal proteins were detected in all experimental assays, but they differed in their expression level according to the temperature and growth phase conditions (Table 1). The ribosomal proteins identified were the 50S proteins L1 (CV4196), L3 (CV4186), L4 (CV4185), L5 (CV4174), L6 (CV4171), and L9 (CV3637) and the 30S proteins S6 (CV3640) and S7 (CV4190). 

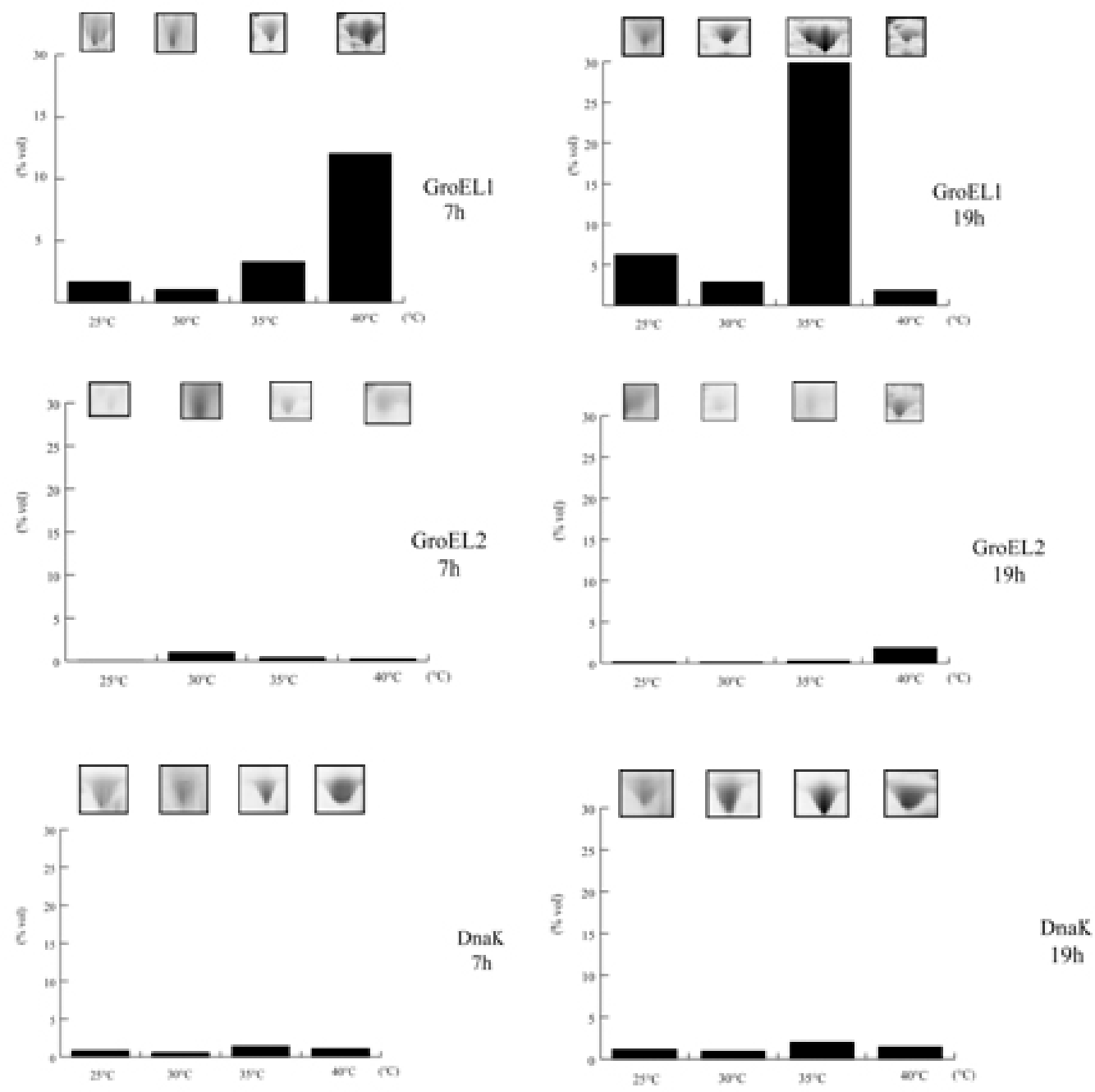

Figure 4. Effect of the temperature and growth phase on the metabolic enzymes of Chromobacterium violaceum. The values $(\%$ vol) were determined by Image Master Platinum. The spots that were identified under each experimental condition are shown in detail.

\section{Transport/secretion and membrane related proteins}

Six proteins that play roles in the transport or secretion of metabolites and one related to membranes were detected: a proton/sodium glutamate symport protein (CV3409), an oligopeptide likely involved in substrate binding in the ABC transporter system (CV4329), a probable multidrug efflux protein (CV3524), an ABC dipeptide transporter (CV1097) and an outer membrane protein A (CV3571) were observed under all conditions tested. Expression was altered by conditions testing for a probable secretion protein (CV0069), which was detected under all conditions tested except at $40^{\circ} \mathrm{C}$ (stationary phase), and for a probable amino acid 
permease transmembrane protein $(\mathrm{CV} 0871)$, which was observed in stationary phase $\left(30^{\circ} \mathrm{C}\right)$ and exponential phase $\left(35\right.$ and $\left.40^{\circ} \mathrm{C}\right)($ Table 1$)$.

\section{DISCUSSION}

Molecular chaperones are essential for the correct folding of proteins (Techtmann and Robb, 2010) and confer protection against the formation of cellular protein aggregates (Henry et al., 2011). The GroEL1 and GroEL2 chaperones that were identified in C. violaceum shared $76 \%$ amino acid sequence similarity (http://www.brgene.lncc.br/cviolaceum) and are probably expressed from paralogous genes, as described for Mycobateria (Ojha et al., 2005) and Myxococcus xanthus (Li et al., 2010). In these microorganisms, the amino acid similarity between the groEL1 and groEL2 genes was 60 and $79 \%$, respectively.

DnaK, GroEL1 and GroEL2 chaperones were expressed under all conditions tested, but increased expression of GroEL1 was correlated with heat stress (Figure 3). These results suggest that these temperatures are stressful and that the GroEL1 heat shock protein is the main chaperone required for the adaptation of $C$. violaceum to thermal stress, as described for M. xanthus (Li et al., 2010). This result reinforces that $30^{\circ} \mathrm{C}$ is the optimum growth temperature for $C$. violaceum, in accordance with a review by Hungria et al. (2004). In addition, it was previously demonstrated that, in Streptococcus mutans, the expression of proteins related to bacterial cell adhesion was dependent upon the heat shock proteins DnaK and GroEL, suggesting that these chaperones are involved in other cellular processes besides stress response (Ishibashi et al., 2010). This is consistent with the results shown in this work, as heat shock protein chaperones were expressed under all tested conditions.

We observed an increase in the expression of a small heat shock protein (sHSP) of approximately $15 \mathrm{kDa}$ in size at 35 and $40^{\circ} \mathrm{C}$ in both the exponential and stationary phases. Typically, sHSP plays a role like other chaperones, as it binds to other proteins, enabling protein folding and preventing protein aggregation (Murata et al., 2011). The temperature-driven expression of this sHSP, as well as the presence of a consensus heat shock $\sigma^{32}$ sigma factor binding site in its promoter, reinforces the notion that temperatures equal to or greater than $35^{\circ} \mathrm{C}$ represent heat shock conditions for $C$. violaceum.

The operons for chaperones usually contain IRs, and these regulatory sequences may contribute to the heat shock response by two mechanisms. They may function as regulatory sites of the heat shock genes (Zuber and Schumman, 1994) not undergoing transcription, or they may contribute to the stability of the mRNA when transcribed (Segal and Ron, 1995). CIRCE regions may be recognized by the heat shock responsive transcription regulator, HrcA (Techtmann and Robb, 2010). Usually, these sequences are located upstream or downstream of the promoter region, with variation observed among individual organisms, and they may be crucial for understanding the heat shock response in $C$. violaceum. The differences reported here between the promoter regions of groEL1, groEL2 and dnaK genes, particularly the lack of probable CIRCE elements in groEL2 and dnaK genes, could explain the higher expression observed for GroEL1 protein under thermal stress.

Polyhydroxyalkanoic acids (PHA) are polyesters naturally produced by microorganisms that are known to serve as sources of energy and to function as carbon reserves (Singh et al., 2009). Phasins are proteins that play roles in PHA granule formation (de Almeida et al., 2007) and stabilization of the PHA granule membranes in the cytoplasm of the cell (Ko- 
libachuk et al., 1999), whose expression is thermally regulated (Ting et al., 2010). Although polyhydroxyalkanoate synthase, which has been described in the genome of $C$. violaceum (CV2789, http://www.brgene.lncc.br/cviolaceum), was not identified here, we suggest that the phasin-like protein contributes to the establishment of PHA granules by an unknown mechanism in C. violaceum during stress response.

Iron is important in several enzymatic processes (Faraldo-Gómez and Sansom, 2003; Eisenhauer et al., 2005). It was demonstrated that the $f h u$ operon contributes to the growth of the Gram-negative bacterium by assisting in the uptake and transport of iron (Morton et al., 2010). In C. violaceum, the ferrichrome-iron outer membrane receptor protein and an ATP-dependent transporter are involved in iron acquisition (Hungria et al., 2004). Although the corresponding proteins were not identified in this work, ORFs coding for several proteins associated with the transport of iron-siderophores besides $f h u A$ are present in the $C$. violaceum genome. These include CV1487 and CV1488 (inner membrane iron siderophore $\mathrm{ABC}$ transporters), CV1489 (a periplasmic solute-binding protein of an iron siderophore ABC transporter) and CV2234 (a putative iron siderophore uptake system ATP-binding component) (Vasconcelos et al., 2003). The presence of a probable promoter region recognized by $\sigma^{32}$ sigma factor for $f h u A$ gene corroborates the hypothesis that the ferrichrome-iron receptor is required for the temperature stress adaptation mechanism of $C$. violaceum, even though by an unknown mechanism.

Exposure of the bacterium to heat stress, even under aerobic conditions, imposes an oxidative stress that can induce the heat shock response in bacteria and eukaryotic organisms (Balamurugan and Dugan, 2010). Thus, it is thought that the two stressors may trigger similar responses. Though SOD is typically related to oxidative stress, in agreement with our results, SOD expression has been observed in E. coli cultures grown under high temperature conditions (Aldsworth et al., 1999). Because $C$. violaceum SOD is an iron-dependent enzyme, the observed increase in the expression of the ferrichrome-iron outer membrane receptor protein at high temperatures may account for the observed overexpression of SOD. Two probable elements that are recognized by $\sigma^{32}$ sigma factor in the promoter region of gene coding for SOD were found, corroborating the proposal that SOD contributes during stress response.

Elongation factor $\mathrm{P}(\mathrm{EF}-\mathrm{P})$, detected only at $40^{\circ} \mathrm{C}$ (exponential phase) in the present investigation, directly stimulates protein elongation (Greganova et al., 2011; Pech et al., 2011), yet its precise mode of action at the ribosome is unclear. As previously discussed, many different types of stress elicit a complex series of events that confer adaptability on microorganisms (England et al., 2011). Therefore, we suggest that EF-P is required under higher demand in cells grown under heat stress, where they would be necessary to maintain the translation of myriad different proteins. Other works have shown that ribosome and ribosome-associated factors contribute to stress adaptation (Pech et al., 2011), corroborating our results.

Ornithine carbamoyltransferase participates in the biosynthesis of amino acids through the production of fumarate, which is the final acceptor of electrons in $C$. violaceum under anaerobic conditions (Vasconcelos et al., 2003). Although C. violaceum is a facultative anaerobic bacterium, the expression levels of ornithine carbamoyltransferase were comparable to proteins related to thermal stress, suggesting that stressful temperatures could result in the activation of metabolic pathways that are also utilized under anaerobic conditions. Even though ornithine carbamoyltransferase protein was expressed only under stress condition in C. violaceum, its regulatory region has been analyzed, and it is likely that $\sigma^{70}$ sigma factor can 
bind to this region (data not shown). Additional investigations are required to identify regulatory regions related to thermal stress response.

As opposed to chaperones and other proteins that are associated with heat stress, the highest expression levels of proteins related to the respiratory and fermentation cycles were observed at $30^{\circ} \mathrm{C}$ (Figure 4). This reinforces the notion that $30^{\circ} \mathrm{C}$ is the optimal growth temperature for $C$. violaceum under the conditions investigated. The regulatory regions of the genes coding for the proteins described in this section were analyzed. Their probable promoter regions may interact with $\sigma^{70}$ sigma factor (data not shown).

Ribosomal proteins have been shown to be involved in the modulation of protein translation under environmentally stressful conditions (Singh et al., 2009; Hamon et al., 2011; Murata et al., 2011). Nevertheless, ribosomal proteins were detected in all conditions tested in this work, though at variable levels of expression. No heat shock-related regulatory motif was found in the promoter sequences of the ribosomal genes and we suggest that ribosomal proteins detected in this investigation were expressed in a constitutive fashion.

Usually, bacteria that have the capacity to adapt to various environments harbor $\mathrm{ABC}$ (ATP binding cassette) transport proteins (Higgins, 2001). In the $C$. violaceum genome, $2.7 \%$ of all ORFs encode transporter proteins, of which $80 \%$ are $\mathrm{ABC}$ transporter proteins (Grangeiro et al., 2004). In this work, the $\mathrm{ABC}$ transporters identified were highly expressed at $30^{\circ} \mathrm{C}$ in exponential phase (data not shown). These proteins are likely associated with the increase in primary metabolism that was observed during the exponential growth phase at the optimal growth temperature, as discussed before. The proton/sodium glutamate symport protein (CV3409) is involved in the transport of glutamate, an important carbon source, across the membrane through a system involving the co-transport of protons and sodium (Raunser et al., 2006). This protein is known to be expressed under nutrient-limiting conditions. In the present work, glutamate symport levels increased in cells grown at 25 and $35^{\circ} \mathrm{C}$ during the exponential growth phase (data not shown) in contrast to that observed for metabolic enzymes. This upregulation may represent a response to a decreased function of the primary metabolic pathways, such as glycolysis, which may also occur during carbon and nitrogen starvation. However, more studies need to be performed to explore the contribution of transport proteins in different adaptation strategies of $C$. violaceum to adverse conditions such as thermal, oxidative and starvation stresses.

In conclusion, even though the complete scenario for stress adaptation for $C$. violaceum was not pictured, the involvement of chaperones and other proteins that typically contribute to adaptation in stressful conditions was demonstrated. To better understand the contribution of these proteins and their regulatory elements, the promoter regions of genes related to heat stress in $C$. violaceum have been isolated and cloned, and studies of their activities under different temperatures are in progress. The work presented here provides new insight into the genome and proteome of $C$. violaceum.

\section{ACKNOWLEDGMENTS}

Research supported by CNPq, FAPEAM, CAPES, and FINEP. This study was carried out by the Amazon Proteomic Network (PROTEAM). We thank Dr. Fabio C. Gozzo at the Synchrotron Light National Lab, LNLS for allowing us to perform mass spectrometry experiments. 


\section{REFERENCES}

Aldsworth TG, Sharman RL and Dodd CE (1999). Bacterial suicide through stress. Cell Mol. Life Sci. 56: 378-383.

Balamurugan S and Dugan ME (2010). Growth temperature associated protein expression and membrane fatty acid composition profiles of Salmonella enterica serovar Typhimurium. J. Basic Microbiol. 50: 507-518.

Beavis RC, Chaudhary T and Chait BT (1992). $\alpha$-Cyano-4-hydroxycinnamic acid as a matrix for matrix-assisted laser desorption mass spectrometry. Org. Mass Spectrom. 27: 156-158.

Bergonzini C (1881). Um nuevo bacterio colorato. Annu. Soc. Nat. Mod. Ser. 2: 149-158.

Broberg CA and Clark DD (2010). Shotgun proteomics of Xanthobacter autotrophicus Py2 reveals proteins specific to growth on propylene. Arch. Microbiol. 192: 945-957.

de Almeida A, Nikel PI, Giordano AM and Pettinari MJ (2007). Effects of granule-associated protein PhaP on glyceroldependent growth and polymer production in poly(3-hydroxybutyrate)-producing Escherichia coli. Appl. Environ. Microbiol. 73: 7912-7916.

Eisenhauer HA, Shames S, Pawelek PD and Coulton JW (2005). Siderophore transport through Escherichia coli outer membrane receptor FhuA with disulfide-tethered cork and barrel domains. J. Biol. Chem. 280: 30574-30580.

El-Samad H, Kurata H, Doyle JC, Gross CA, et al. (2005). Surviving heat shock: control strategies for robustness and performance. Proc. Natl. Acad. Sci. U. S. A. 102: 2736-2741.

England K, Crew R and Slayden RA (2011). Mycobacterium tuberculosis septum site determining protein, Ssd encoded by rv3660c, promotes filamentation and elicits an alternative metabolic and dormancy stress response. BMC Microbiol. 11: 79 .

Faraldo-Gómez JD and Sansom MS (2003). Acquisition of siderophores in gram-negative bacteria. Nat. Rev. Mol. Cell Biol. 4: 105-116.

Gomes LM, Gesteira AS, de Almeida AA, de Castro AV, et al. (2012). Changes in protein profile detected in seedlings of Caesalpinia peltophoroides (Fabaceae) after exposure to high concentration of cadmium. Genet. Mol. Res. 11: 2694-2707.

Grangeiro TB, Jorge DM, Bezerra WM, Vasconcelos AT, et al. (2004). Transport genes of Chromobacterium violaceum: an overview. Genet. Mol. Res. 3: 117-133.

Greganova E, Altmann M and Butikofer P (2011). Unique modifications of translation elongation factors. FEBS J. 278: 2613-2624.

Hamon E, Horvatovich P, Izquierdo E, Bringel F, et al. (2011). Comparative proteomic analysis of Lactobacillus plantarum for the identification of key proteins in bile tolerance. BMC Microbiol. 11: 63.

Henry R, Bruneau E, Gardan R, Bertin S, et al. (2011). The rgg0182 gene encodes a transcriptional regulator required for the full Streptococcus thermophilus LMG18311 thermal adaptation. BMC Microbiol. 11: 223.

Higgins CF (2001). ABC transporters: physiology, structure and mechanism - an overview. Res. Microbiol. 152: 205-210.

Hongsthong A, Sirijuntarut M, Prommeenate P, Lertladaluck K, et al. (2008). Proteome analysis at the subcellular level of the cyanobacterium Spirulina platensis in response to low-temperature stress conditions. FEMS Microbiol. Lett. 288: $92-101$.

Hungria M, Nicolas MF, Guimarães CT, Jardim SN, et al. (2004). Tolerance to stress and environmental adaptability of Chromobacterium violaceum. Genet. Mol. Res. 3: 102-116.

Ishibashi K, Shimada K, Kawato T, Kaji S, et al. (2010). Inhibitory effects of low-energy pulsed ultrasonic stimulation on cell surface protein antigen C through heat shock proteins GroEL and DnaK in Streptococcus mutans. Appl. Environ. Microbiol. 76: 751-756.

Jozefczuk S, Klie S, Catchpole G, Szymanski J, et al. (2010). Metabolomic and transcriptomic stress response of Escherichia coli. Mol. Syst. Biol. 6: 364.

Karas M and Hillenkamp F (1988). Laser desorption ionization of proteins with molecular masses exceeding 10,000 daltons. Anal. Chem. 60: 2299-2301.

Kolibachuk D, Miller A and Dennis D (1999). Cloning, molecular analysis, and expression of the polyhydroxyalkanoic acid synthase (phaC) gene from Chromobacterium violaceum. Appl. Environ. Microbiol. 65: 3561-3565.

Li J, Wang Y, Zhang CY, Zhang WY, et al. (2010). Myxococcus xanthus viability depends on groEL supplied by either of two genes, but the paralogs have different functions during heat shock, predation, and development. J. Bacteriol. 192: $1875-1881$.

Lima-Bittencourt CI, Costa PS, Hollatz C, Raposeiras R, et al. (2011). Comparative biogeography of Chromobacterium from the neotropics. Antonie Leeuwenhoek 99: 355-370.

Morton DJ, Turman EJ, Hensley PD, VanWagoner TM, et al. (2010). Identification of a siderophore utilization locus in nontypeable Haemophilus influenzae. BMC Microbiol. 10: 113. 
Murata M, Fujimoto H, Nishimura K, Charoensuk K, et al. (2011). Molecular strategy for survival at a critical high temperature in Eschierichia coli. PLoS One 6: e20063.

Nonaka G, Blankschien M, Herman C, Gross CA, et al. (2006). Regulon and promoter analysis of the E. coli heat-shock factor, sigma32, reveals a multifaceted cellular response to heat stress. Genes Dev. 20: 1776-1789.

O'Farrell PH (1975). High resolution two-dimensional electrophoresis of proteins. J. Biol. Chem. 250: 4007-4021.

Ojha A, Anand M, Bhatt A, Kremer L, et al. (2005). GroEL1: a dedicated chaperone involved in mycolic acid biosynthesis during biofilm formation in mycobacteria. Cell 123: 861-873.

Pech M, Karim Z, Yamamoto H, Kitakawa M, et al. (2011). Elongation factor 4 (EF4/LepA) accelerates protein synthesis at increased $\mathrm{Mg}^{2+}$ concentrations. Proc. Natl. Acad. Sci. U. S. A. 108: 3199-3203.

Raunser S, Appel M, Ganea C, Geldmacher-Kaufer U, et al. (2006). Structure and function of prokaryotic glutamate transporters from Escherichia coli and Pyrococcus horikoshii. Biochemistry 45: 12796-12805.

Rossignol T, Kobi D, Jacquet-Gutfreund L and Blondin B (2009). The proteome of a wine yeast strain during fermentation, correlation with the transcriptome. J. Appl. Microbiol. 107: 47-55.

Rowbury RJ (2005). Intracellular and extracellular components as bacterial thermometers, and early warning against thermal stress. Sci. Prog. 88: 71-99.

Segal G and Ron EZ (1995). The groESL operon of Agrobacterium tumefaciens: evidence for heat shock-dependent mRNA cleavage. J. Bacteriol. 177: 750-757.

Singh M, Patel SK and Kalia VC (2009). Bacillus subtilis as potential producer for polyhydroxyalkanoates. Microb. Cell Fact. 8: 38.

Techtmann SM and Robb FT (2010). Archaeal-like chaperonins in bacteria. Proc. Natl. Acad. Sci. U. S. A. 107: 2026920274.

Ting L, Williams TJ, Cowley MJ, Lauro FM, et al. (2010). Cold adaptation in the marine bacterium, Sphingopyxis alaskensis, assessed using quantitative proteomics. Environ. Microbiol. 12: 2658-2676.

Vasconcelos ATR, Almeida DF, Hungria M, Guimarães CT, et al. (2003). The complete genome sequence of Chromobacterium violaceum reveals remarkable and exploitable bacterial adaptability. Proc. Natl. Acad. Sci. U. S. A. 100: 11660-11665.

Woo PC, Lau SK, Tse H, Teng JL, et al. (2009). The complete genome and proteome of Laribacter hongkongensis reveal potential mechanisms for adaptations to different temperatures and habitats. PLoS Genet. 5: e1000416.

Yura T, Nagai H and Mori H (1993). Regulation of the heat-shock response in bacteria. Annu. Rev. Microbiol. 47: 321-350.

Zuber U and Schumann W (1994). CIRCE, a novel heat shock element involved in regulation of heat shock operon dnaK of Bacillus subtilis. J. Bacteriol. 176: 1359-1363. 